\title{
The impact of model grid zooming on tracer transport in the 1999/2000 Arctic polar vortex
}

\author{
M. M. P. van den Broek ${ }^{1}$, M. K. van Aalst ${ }^{2}$, A. Bregman ${ }^{3}$, M. Krol' ${ }^{2}$, J. Lelieveld ${ }^{4}$, G. C. Toon ${ }^{5}$, S. Garcelon ${ }^{6}$, \\ G. M. Hansford ${ }^{6}$, R. L. Jones ${ }^{6}$, and T. D. Gardiner ${ }^{7}$ \\ ${ }^{1}$ Space Research Organization of the Netherlands (SRON), Utrecht, The Netherlands \\ ${ }^{2}$ Institute for Marine and Atmospheric Research (IMAU), Utrecht, The Netherlands \\ ${ }^{3}$ Royal Netherlands Meteorological Institute (KNMI), De Bilt, The Netherlands \\ ${ }^{4}$ Max-Planck-Institut für Chemie (MPI), Mainz, Germany \\ ${ }^{5}$ Jet Propulsion Laboratory (JPL), Pasadena, USA \\ ${ }^{6}$ Cambridge University, Cambridge, UK \\ ${ }^{7}$ National Physical Laboratory (NPL), Teddington, UK
}

Received: 27 January 2003 - Published in Atmos. Chem. Phys. Discuss.: 9 May 2003

Revised: 8 October 2003 - Accepted: 17 October 2003 - Published: 31 October 2003

\begin{abstract}
We have used a 3-D chemistry transport model to evaluate the transport of $\mathrm{HF}$ and $\mathrm{CH}_{4}$ in the stratosphere during the Arctic winter of 1999/2000. Several model experiments were carried out with the use of a zoom algorithm to investigate the effect of different horizontal resolutions. Balloon-borne and satellite-borne observations of HF and $\mathrm{CH}_{4}$ were used to test the model. In addition, air mass descent rates within the polar vortex were calculated and compared to observations.

Outside the vortex the model results agree well with the observations, but inside the vortex the model underestimates the observed vertical gradient in $\mathrm{HF}$ and $\mathrm{CH}_{4}$, even when the highest available resolution $\left(1^{\circ} \times 1^{\circ}\right)$ is applied. The calculated diabatic descent rates agree with observations above potential temperature levels of $450 \mathrm{~K}$. These model results suggest that too strong mixing through the vortex edge could be a plausible cause for the model discrepancies, associated with the calculated mass fluxes, although other reasons are also discussed.

Based on our model experiments we conclude that a global $6^{\circ} \times 9^{\circ}$ resolution is too coarse to represent the polar vortex, whereas the higher resolutions, $3^{\circ} \times 2^{\circ}$ and $1^{\circ} \times 1^{\circ}$, yield similar results, even with a $6^{\circ} \times 9^{\circ}$ resolution in the tropical region.
\end{abstract}

Correspondence to: M. M. P. van den Broek

(broekvd@knmi.nl)

\section{Introduction}

Both 2-D and 3-D Chemistry Transport Models (CTMs) are widely used to evaluate the understanding of atmospheric processes and to study how possible future changes in emissions will affect the composition and state of the atmosphere. One important focus of stratospheric research with CTMs is the depletion of ozone, notably in the polar vortex and at mid-latitudes. Both transport and chemical processes influence the ozone concentration, while its variability is mainly determined by dynamics (Chipperfield and Jones, 1999). To model stratospheric ozone and to estimate chemical ozone loss, it is therefore of great importance that ozone transport is modeled realistically.

Several studies tested modeled transport and investigated the related key model properties. In a 2-D latitude-longitude study on ozone depletion, Edouard et al. (1996) found a large impact of increasing horizontal resolution. Searle et al. (1998) repeated this study with contradictory results. Since both these studies concentrate on ozone depletion, both chemistry and transport are expected to influence this result.

One method to evaluate model transport separately is by simulating long-lived tracers, which can then be tested against observations. HF, for example, is such a tracer, which is used in this study. In an earlier model evaluation, Chipperfield et al. (1997) also simulated HF. They found a good agreement with observations, except in polar air where HF columns were underestimated. Rind et al. (1999) used CFC11 and SF6 to evaluate model transport across the tropopause and found no improvement when they increased the vertical resolution of their general circulation model (GCM). They suggested that dynamical properties such as wave drag and 


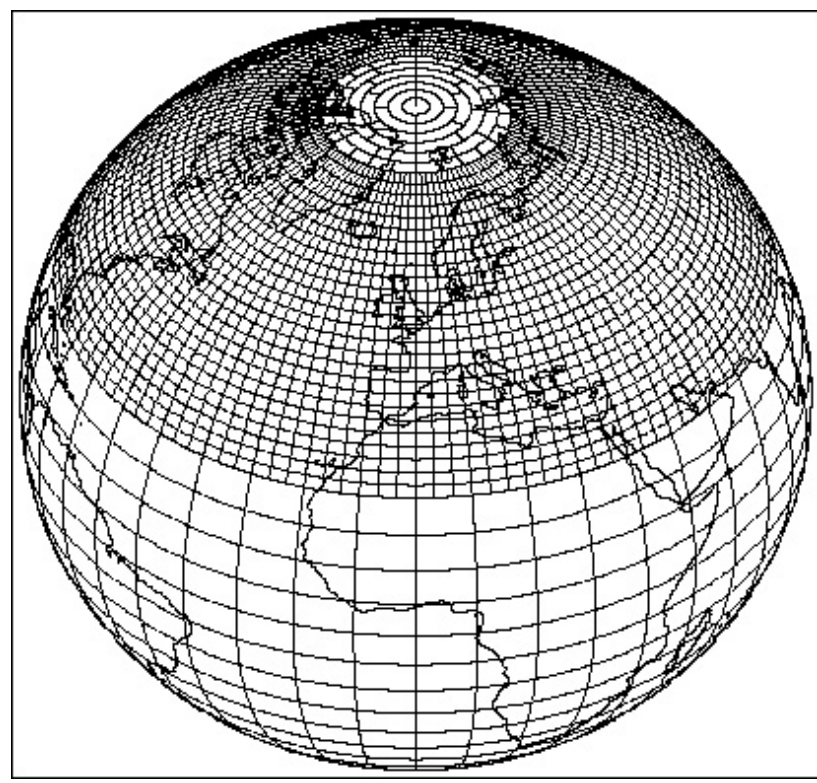

Fig. 1. An illustration of the horizontal zoom grid of TM5. Zoom option G196_NH32 is shown here.

top altitude of the model should be improved with priority. Mahowald et al. (2002) point out that the choice of the vertical coordinate system, based on pressure or isentropes, impacts tracers such as water vapor and the age of air in the tropical stratosphere, with the isentropic coordinate system giving less diffusive and more realistic model results. A recent model intercomparison among 2-D models and 3-D CTMs showed that the calculated age of air was too low in almost all models (Hall et al., 1999). However, more recent analysis showed that the descent rates inside the polar vortex in the 3-D CTMs SLIMCAT and REPROBUS agreed reasonably well with observations (Greenblatt et al., 2002). Plumb et al. (2002) modeled transport of $\mathrm{N}_{2} \mathrm{O}$ in the polar vortex for the same winter using the CTM MATCH. They found that $\mathrm{N}_{2} \mathrm{O}$ was overestimated in the lower stratospheric vortex and suggested that cross-vortex boundary transport was not accurately calculated or that inner-vortex mixing was too intense. It was suggested that this was related to the underlying meteorological data, since doubling their original horizontal resolution of $2.8^{\circ} \times 2.8^{\circ}$ did not make a difference. Another study of $\mathrm{N}_{2} \mathrm{O}$ and $\mathrm{NOy}$ transport during this winter showed that increasing the vertical resolution did not improve the comparison of model results with observations either (Considine et al., 2003).

In this study we explore the effect of horizontal resolution and of using a zoom region on tracer distributions in more detail by model simulations of $\mathrm{HF}$ and $\mathrm{CH}_{4}$ during the 1999/2000 winter, focusing on the Arctic polar vortex. We also evaluate diabatic descent rates to interpret the calculated tracer distributions. We employ the newly developed chemistry transport model TM5 (Krol et al., 2003) to simulate
$\mathrm{HF}$ and $\mathrm{CH}_{4}$. TM5 contains a 2-way nesting zooming algorithm (Krol et al., 2001), which is employed here to study the effect of resolution changes on transport. $\mathrm{HF}$ and $\mathrm{CH}_{4}$ are long-lived in the stratosphere and have lifetimes over 1 year below $10 \mathrm{hPa}$, and are therefore solely influenced by transport on shorter timescales. HF is produced in the upper stratosphere by photochemical breakdown of CFCs. It has no chemical sinks in the stratosphere and its only known loss mechanism is downward transport and subsequent wet deposition in the troposphere. $\mathrm{CH}_{4}$ has the inverse profile, with higher values in the troposphere due to emissions at the earth surface from biogenic and anthropogenic activity. Concentrations drop with increasing altitude due to chemical loss by photo-dissociation and reaction with $\mathrm{OH}, \mathrm{O}^{1} \mathrm{D}$ and $\mathrm{Cl}$ in the stratosphere and reaction with $\mathrm{OH}$ in the troposphere.

An important reason to focus on the 1999/2000 winter is the availability of observations of $\mathrm{HF}$ and $\mathrm{CH}_{4}$ from the combined SOLVE (Sage III Ozone Loss and Validation Experiment) and THESEO (THird European Stratospheric Experiment on Ozone) campaigns. Furthermore, a distinct polar vortex formed in the lower stratosphere after December 1st (Manney and Sabutis, 2000), which provides a good test case to study the isolation of the vortex.

We investigate modeled tracer distributions employing three different horizontal resolutions in the northern hemisphere, ranging from $9^{\circ}$ longitude by $6^{\circ}$ latitude to $1^{\circ}$ longitude by $1^{\circ}$ latitude. Van Aalst et al. (2003) carried out a model study with the same experimental set-up, using the MA-ECHAM climate model with assimilated meteorological data of the same time period.

The model experiments and the observations used are described in Sect. 2. Section 3 presents the model results and compares with the observations. A sensitivity test on the model initialization is carried out in Sect. 3.6. Discussion and conclusions follow in Sect. 4.

\section{Model experiments}

\subsection{Model description}

We have used the new global three-dimensional transport model, version 5 (TM5). The model is an extended version of the TM3 model that has been used in several previous stratospheric studies (Van den Broek et al., 2000; Bregman et al., 2000; Bregman et al., 2001). The new model is able to zoom horizontally over a certain area, e.g. Europe or the polar vortex, by selectively increasing the horizontal resolution. Krol et al. (2001) explain the mass conserving two-way nesting algorithm and show first model results for tropospheric ${ }^{222} \mathrm{Rn}$. Figure 1 gives an impression of the zooming options in TM5 used in this study. Meteorological input for the model is provided by six-hourly ECMWF (European Centre for Medium-Range Weather Forecasts) forecast fields of temperature, surface pressure, wind and humidity. The data 
Table 1. An overview of the different horizontal resolutions used in this study

\begin{tabular}{lll}
\hline & Region 1 (global) lon $\times$ lat & Region 2 (zoom) lon $\times$ lat \\
\hline Gl_96 & $9^{\circ} \times 6^{\circ}$ & \\
G196_NH32 & $9^{\circ} \times 6^{\circ}$ & $3^{\circ} \times 2^{\circ}\left(24^{\circ} \mathrm{N}-90^{\circ} \mathrm{N}\right)$ \\
G1_32 & $3^{\circ} \times 2^{\circ}$ & \\
G132_NP11 & $3^{\circ} \times 2^{\circ}$ & $1^{\circ} \times 1^{\circ}\left(30^{\circ} \mathrm{N}-90^{\circ} \mathrm{N}\right)$ \\
\hline
\end{tabular}

extend up to $0.2 \mathrm{hPa}$. The method to calculate mass fluxes from ECMWF winds has recently been improved (Bregman et al., 2003). We used a 33-layer subset of the 60 layer fields that are taken into account in the ECMWF model, with a reduced number of levels in the tropospheric boundary layer and above $70 \mathrm{hPa}$. Before 12 October 1999 the ECMWF model used 50 vertical layers from which we derived a subset of 30 layers. Near the surface the model levels are defined as terrain following sigma coordinates whereas the layers above $100 \mathrm{hPa}$ are defined at pressure surfaces. A hybrid of the two is used between the lower levels and the lower stratosphere. An example of the vertical grid in TM5, assuming a surface pressure of $1000 \mathrm{hPa}$, is shown in Fig. 2 together with the original ECMWF grid.

A mass flux advection scheme, using first order slopes (Russell and Lerner, 1981), is used to calculate tracer transport. A dynamical time step of $1800 \mathrm{~s}$ is applied for the coarsest grid $\left(6^{\circ}\right.$ latitude by $9^{\circ}$ longitude). For the $1^{\circ}$ by $1^{\circ}$ resolution a time step of $225 \mathrm{~s}$ is employed. Over the poles, the grid is reduced to avoid numerical instability through violation of the Courant Friedrichs-Lewy (CFL) condition (see Fig. 1). The physical parameterization of boundary layer diffusion and convection are identical to those of the TM3 model (Peters et al., 2002), For instance, convection is calculated with the Tiedtke (1989) mass flux parameterization for cumulus clouds, including entrainment and detrainment in updrafts and downdrafts.

\subsection{Experimental set-up}

In this study, $\mathrm{HF}$, and $\mathrm{CH}_{4}$ are simulated for the Arctic winter of 1999-2000. Four zooming options have been investigated (see Table 1), with a horizontal model resolution ranging from $9^{\circ}$ longitude by $6^{\circ}$ latitude globally, up to $1^{\circ}$ by $1^{\circ}$ from $30^{\circ}$ to $90^{\circ} \mathrm{N}$.

The model integrations start at 1 September 1999. Initialization is based on zonally averaged observations of the HALOE (HALogen Occultation Experiment) sunset sweep of 7 August to 22 September 1999, which ranged from $73.9^{\circ} \mathrm{N}$ to $63.5^{\circ} \mathrm{S}$. In regions for which observations are not available (at the poles, in the troposphere and in a gap in the HALOE data between $43^{\circ} \mathrm{N}$ and $62^{\circ} \mathrm{N}$ ), the initial concentrations are linearly inter- or extrapolated from nearby latitudes. In the vertical direction, we prescribe tropo-

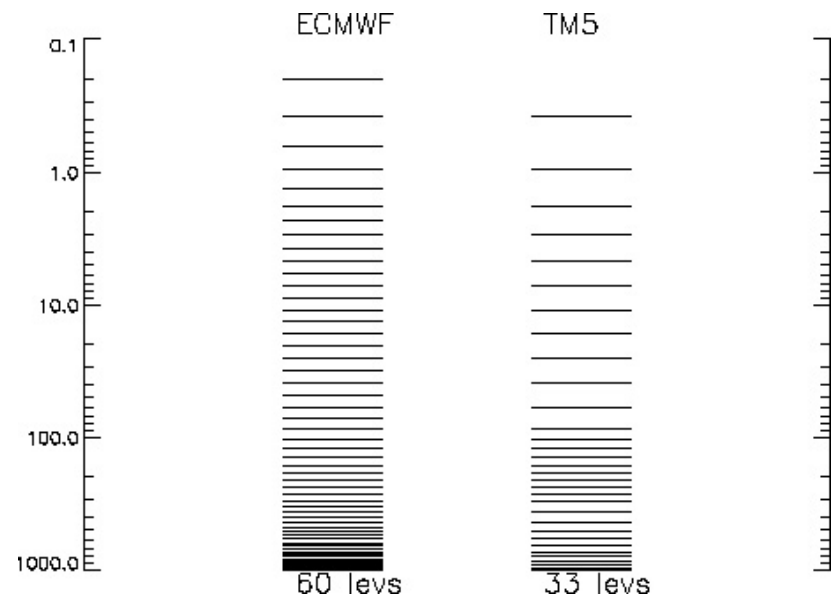

Fig. 2. The vertical grid of TM5 and the original ECMWF vertical grid.

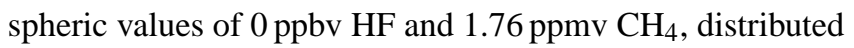
slightly over the two hemispheres by adding a $0.02 \mathrm{ppmv}$ sine function. A log-pressure interpolation is applied when no HALOE data are available at a certain altitude.

Removal of HF by wet deposition has been implemented in TM 5 by assuming a lifetime of 5 days below $400 \mathrm{hPa}$, as in Chipperfield et al. (1997). In the top two levels $\mathrm{CH}_{4}$ and $\mathrm{HF}$ are constrained with monthly zonally averaged UARS data (Randel et al., 1998), since chemical production (of HF) and destruction $\left(\right.$ of $\left.\mathrm{CH}_{4}\right)$ are not included in the model. Sensitivity runs carried out by Van Aalst et al. (2003) show that stratospheric washout of HF and prescribing the top boundary concentrations for both tracers have only a small or negligible effect on the tracer fields for the integration period considered in this study. In addition, they found that ignoring chemical destruction of $\mathrm{CH}_{4}$ causes a small deviation of less than $10 \%$, and only above $20 \mathrm{hPa}$.

\subsection{Observations during the 1999-2000 winter}

The lower stratosphere was extremely cold during the Arctic winter of 1999-2000, especially in the early winter. Despite these low temperatures, the lower stratospheric vortex was weak until December and formed slowly compared to other cold winters. In the upper and middle stratosphere, a distinct vortex was already discernable on 1 November. By the end of December, the vortex was established throughout the stratosphere (Manney and Sabutis, 2000).

Several measurements of $\mathrm{CH}_{4}$ and $\mathrm{HF}$ were used for comparison with the model results. (i) The balloon-borne Tunable Diode Laser Absorption Spectrometer (TDLAS) measured in-situ profiles of $\mathrm{CH}_{4}$. The flights took place on 28 January, 9, 13, and 27 February and 25 March 2000 and samples were taken inside, outside and at the edge of the vortex (Garcelon et al., 2002). (ii) Balloon-borne observations of $\mathrm{HF}$ and $\mathrm{CH}_{4}$ were carried out with the JPL MkIV 


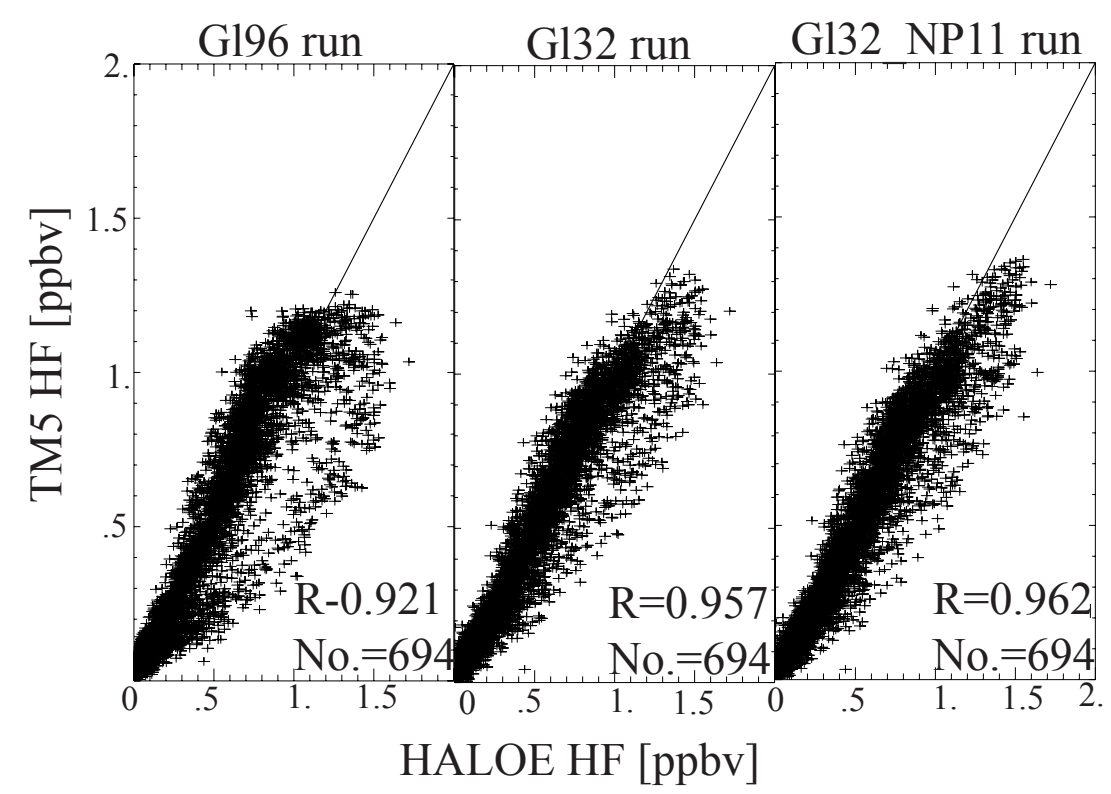

Fig. 3a. Correlation between HALOE observations and TM5 model output for three different model resolutions: G196 $\left(9^{\circ} \times 6^{\circ}\right)$, G132 $\left(3^{\circ} \times 2^{\circ}\right)$ and G132_NP11 $\left(1^{\circ} \times 1^{\circ}, 3^{\circ} \times 2^{\circ}\right.$ south of $\left.30^{\circ} \mathrm{N}\right)$, from December 1999 to March 2000 , north of $30^{\circ} \mathrm{N}$ and pressure $<150 \mathrm{hPa}$. The number of profiles used is given as well.

interferometer (Toon et al., 1999) in the inner vortex; both at the start of vortex formation on 3 December 1999 and close to vortex break up on 15 March 2000. (iii) The HALOE instrument observed both $\mathrm{CH}_{4}$ and $\mathrm{HF}$, collecting 8-15 profiles each day at two latitude bands (Russell et al., 1993). Usually, HALOE observations do not extend poleward far enough to reach the vortex, but on 20 February 2000 at $56^{\circ} \mathrm{N}$ some profiles were obtained at the edge of the vortex.

All these observations have been compared with the TM5 results. In addition, diabatic descent rates within the vortex, calculated by the model, have been compared with those derived from $\mathrm{CH}_{4}$ observations (Greenblatt et al., 2002).

\section{Results}

\subsection{HALOE HF profiles}

The HALOE instrument has sampled many mid-latitude profiles of HF during the '99-' 00 winter. The errors within the HALOE HF profiles are small. The mean difference between HALOE HF and correlative balloon underflight measurements is less than $7 \%$ in the altitude range between $5 \mathrm{hPa}$ and $50 \mathrm{hPa}$ (Russell et al., 1996).

All available Northern hemispheric mid-latitude HALOE HF observations from December 1999 to March 2000 have been compared to the modeled fields. North of $30^{\circ} \mathrm{N}, 649$ profiles were measured in total. The bulk of the measurements were carried out outside the polar vortex. Figures $3 \mathrm{a}$ and $b$ show the correlations of these observations with the TM5 model results. The TM5 results have been matched with the measurements by using the results of the model gridbox and time zone (within 12 hours) in which the HALOE data were observed. Since the HALOE instrument produces a high vertical resolution compared to the TM5 model, HALOE observations within one TM5 vertical layer have been averaged. Figure $3 \mathrm{a}$ shows all correlations for 3 different horizontal model resolutions: $9^{\circ} \times 6^{\circ}(\mathrm{Gl} 196), 3^{\circ} \times 2^{\circ}$ $(\mathrm{Gl} 32)$ and $1^{\circ} \times 1^{\circ}\left(\mathrm{Gl} 32\right.$ NP11, with $3^{\circ} \times 2^{\circ}$ south of $\left.30^{\circ} \mathrm{N}\right)$. Independent of resolution, the correlation between the model results and the observations is good. The g169 run shows the largest scatter with a tendency to underestimate the tracer distribution. The results from higher resolutions show much less scatter. Note that the correlation hardly improves any further when going from a $3^{\circ} \times 2^{\circ}$ to a $1^{\circ} \times 1^{\circ}$ resolution. Nevertheless, significant variability is present, even at the highest resolution. We have separated these relationships in time, latitude, and pressure to investigate the origin of this variability. Figure $3 \mathrm{~b}$ shows the results from the gl23 run. The significant underestimation becomes primarily visible at the end of the winter (March) at high latitudes between 50 $100 \mathrm{hPa}$. We have selected 15 March 2000 to show that the samples of this "branch" of data originate from the polar vortex (blue crosses). We therefore compared the model results with all HALOE profiles on 15 March on an equivalent latitude grid at a potential temperature level of $500 \mathrm{~K}$ in Fig. 3c. One can clearly see that the model deviates at high equivalent latitudes. The agreement is good at midlatitudes where all observations fall within the model variability $(2 \sigma)$ for each equivalent latitude bin. This indicates that the model deviations only occur in polar vortex air. 

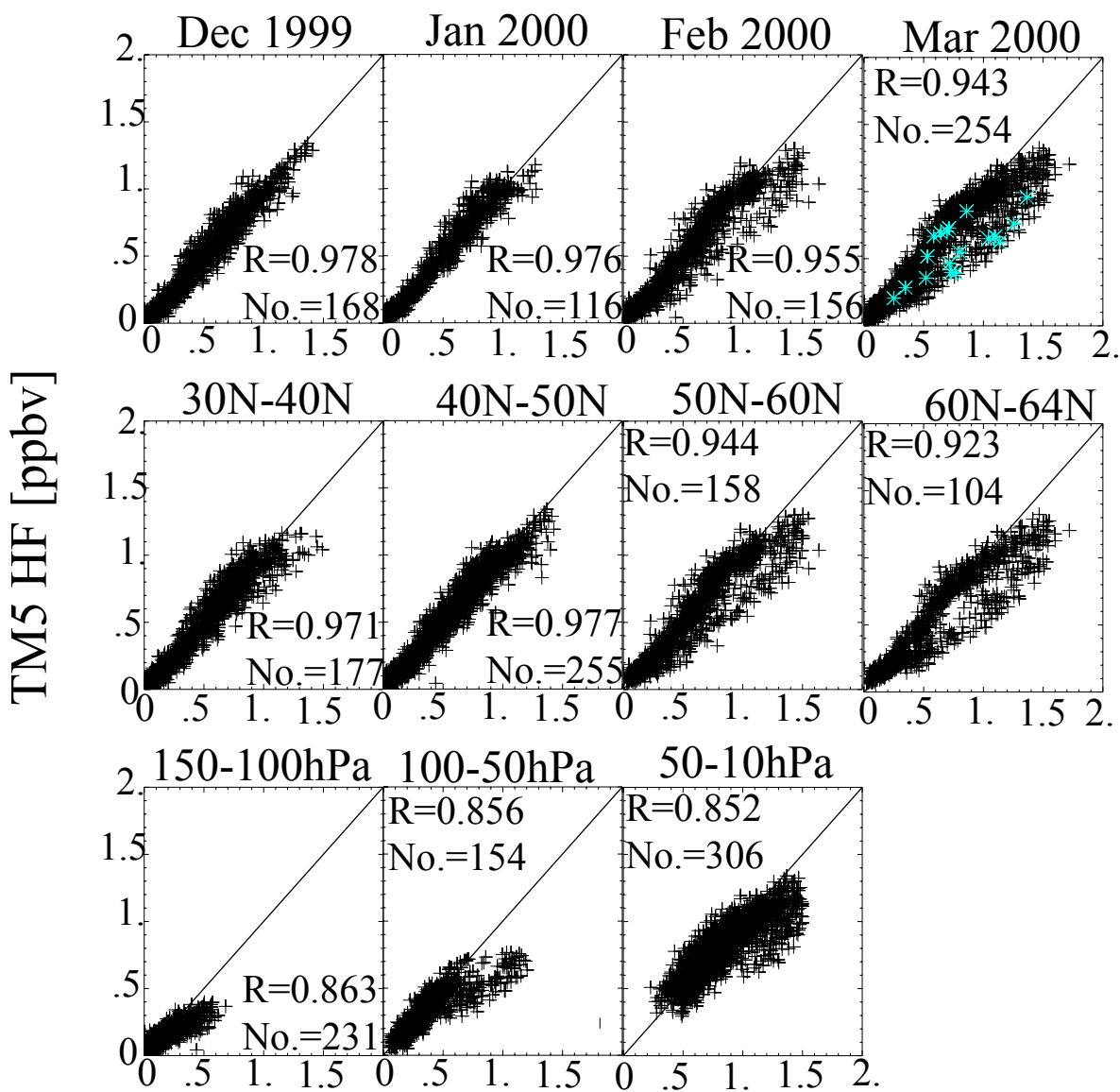

HALOE HF [ppbv]

Fig. 3b. Correlation between HALOE observations and TM5 model output for the G132 run, divided among 4 time periods (December 1999-March 2000), 4 latitudes $\left(30-40^{\circ} \mathrm{N}, 40-50^{\circ} \mathrm{N}, 50-60^{\circ} \mathrm{N}\right.$ and $\left.60-63^{\circ} \mathrm{N}\right)$ and 4 altitude regions $(150-100 \mathrm{hPa}, 100-50 \mathrm{hPa}, 50-10 \mathrm{hPa}$, $10-1 \mathrm{hPa}$ ). For the different time periods and latitudes, the number of profiles is given as well (15 comparisons per profile). The blue crosses denote observations of 15 March between 100 and $50 \mathrm{hPa}$.

\subsection{TDLAS $\mathrm{CH}_{4}$ observations in/out of the vortex}

As a next step, we compared modeled $\mathrm{CH}_{4}$ profiles to $\mathrm{CH}_{4}$ profiles that have been measured by means of the balloonborne TDLAS spectrometer, both inside and outside the polar vortex. The result is shown in Fig. 4a. The estimated error for the observations is about $10 \%$ (Garcelon et al., 2002). Clearly, as in Fig. 3, the model results compare reasonably well with the observations outside the vortex, whereas the model results within and at the inner edge of the vortex indicate significant overestimation. As in Fig. 3, it is remarkable that the model results are very similar for all zooming experiments, including the $1^{\circ}$ by $1^{\circ}$ resolution. The Gl_96 run shows the largest overestimation, implying that this resolution is too coarse for a realistic representation of the tracer distribution.

The good agreement between model and observations outside the vortex was also indicated by the HALOE profile comparisons, especially below $10 \mathrm{hPa}$ (see Fig. 3). However, inside and at the edge of the vortex the $\mathrm{CH}_{4}$ vertical gradient increases with time, which is obviously not fully captured by the model.

Figure $4 \mathrm{~b}$ shows the modeled horizontal gradients on a pressure level of approximately $75 \mathrm{hPa}$ across the vortex edge between Kiruna, the site of the balloon observation, and central Europe on 13 February 2000. The coarser G1_96 model run results in a gradient of $\sim 0.1$ ppmv between Kiruna and central Europe, whereas the G1_32 and NP_11 runs gives a larger gradient of $\sim 0.2$ ppmv. Nevertheless, these gradients are smaller than the differences between the model and the observation at this altitude, which is about $0.35 \mathrm{ppmv}$ (see Fig. 4a). The $1^{\circ}$ by $1^{\circ}$ run does show a sharper gradient, as can be expected, with more distinct features. This may be important when species with large concentration gradients over the vortex edge are studied. 


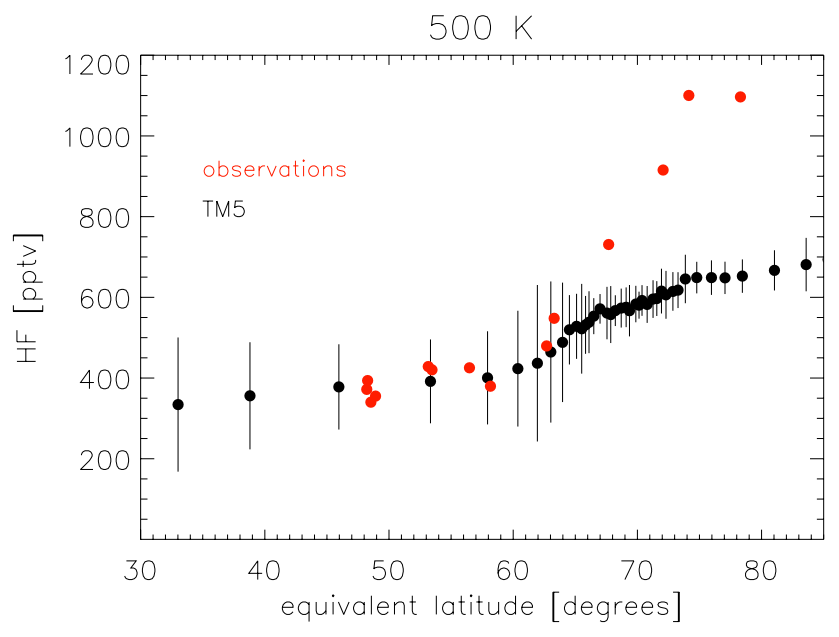

Fig. 3c. HF volume mixing ratio from HALOE observations (asterisks) and TM5 simulations (black dots), along equivalent latitude. Results are shown for 15 March 2000 on the $500 \mathrm{~K}$ potential temperature level. The vertical bars denote the model variability $(2 \sigma)$ for each equivalent latitude bin $\left(2^{\circ}\right)$.

\subsection{MkIV inner vortex observations in early and late winter}

In Fig. 5 TM5 results are compared to $\mathrm{HF}$ and $\mathrm{CH}_{4}$ measurements by the MkIV interferometer, focusing here on the lower stratosphere. The observations were carried out inside the polar vortex in the beginning of winter, on 3 December, when the vortex was just formed in the lower stratosphere, and on 15 March 2000, just before the vortex break-up. Also in this comparison, $\mathrm{HF}$ is consistently underestimated and $\mathrm{CH}_{4}$ is overestimated, both at the beginning and at the end of winter, and the differences between the model runs are similar to the earlier comparisons. However, on 3 December, the difference between model and observation occurs only above $50 \mathrm{hPa}$ while by March 15, the difference is seen throughout the lower stratosphere. Above $15 \mathrm{hPa} \mathrm{HF}$ steeply decreases and $\mathrm{CH}_{4}$ increases on 15 March. PV maps indicate that the MkIV observations above $15 \mathrm{hPa}$ were at the edge of, or outside, the vortex, which explains the gradient reversal. The discrepancies found so early in winter suggest a potential impact from inaccuracies in the initial tracer field. Later we will demonstrate the sensitivity of the model results for the initial tracer fields.

\subsection{HALOE HF longitude cross section}

Fifteen HALOE HF sunrise profiles, observed on 20 February 2002 at $56^{\circ} \mathrm{N}$, have been compiled in a longitudinal graph and are compared with TM5 results (Fig. 6). The HALOE observations comprise both vortex and non-vortex air. For example, the feature with increased HF values between $90^{\circ} \mathrm{E}$ and $60^{\circ} \mathrm{E}$ and $50 \mathrm{~Pa}$ and $10 \mathrm{hPa}$ represents air from the vortex edge. An increased vertical gradient in $\mathrm{HF}$ is visible below this area, between $100 \mathrm{hPa}$ and $20 \mathrm{hPa}$. Another small feature of increased HF is discernable near $100 \mathrm{hPa}$, around $150^{\circ} \mathrm{E}-180^{\circ} \mathrm{E}$.

More obvious than in the previously discussed profile comparisons, the Gl_96 run is too coarse to simulate transport within or across the edge of the vortex, since none of the observed longitudinal features is captured (Fig. 6b). All other model runs capture the observed longitudinal features well and again they produce similar results. On the other hand, the model underestimates the vertical gradient between $100 \mathrm{hPa}$ and $1 \mathrm{hPa}$ at all longitudes, and especially inside the vortex between $150^{\circ} \mathrm{E}$ and $180^{\circ} \mathrm{E}$. This is in agreement with the profile comparisons discussed above (Figs. 4 and 5). The discrepancy between 10 and $1 \mathrm{hPa}$ is also visible in the late winter mid-latitude profiles shown in Fig. 3 and may be attributed to the mixing of vortex air with mid-latitude air.

The vortex air sampled at $56^{\circ} \mathrm{N}$ was situated at the edge, which can be seen from the modeled latitudinal crosssections at $50^{\circ} \mathrm{N}$ and $62^{\circ} \mathrm{N}$ (not shown here). The representation of the vortex edge may contribute to the discrepancies with the observations there, due to the large gradients of HF across the edge of the vortex. At $62^{\circ} \mathrm{N}$ for example, situated more inside the vortex, the sharp vertical gradient matches much better with the HALOE observations at $56^{\circ} \mathrm{N}$ (see also van Aalst et al., 2003).

\subsection{Descent rates}

One likely cause of the model-observations discrepancies could be the underestimate of the diabatic descent by the model. To evaluate the possible origin of these discrepancies, we calculated the modeled vertical descent rates inside the vortex from 1 December to 1 March 2000 and compared those with observed descent rates (i.e. derived from observations). It should be kept in mind that such comparisons do not separate vertical and horizontal transport, so that deviations can be caused by inaccuracies in the mass flux representation in TM5 in both directions. The observed descent is derived from a number of $\mathrm{CH}_{4}$ observations inside the vortex and agrees with calculations carried out with a large number of $\mathrm{N}_{2} \mathrm{O}$ observations (Greenblatt et al., 2002).

Figure 7 shows the decrease of potential temperature along five $\mathrm{CH}_{4}$ isopleths throughout the winter. The black lines shows inner vortex descent calculated from five observed profiles of $\mathrm{CH}_{4}$ during the SOLVE/THESEO campaign [Greenblatt et al., 2002]. The red lines represent the descent of $\mathrm{CH}_{4}$ calculated with TM5. On each first day of the month, zonal winds and PV gradients were used to calculate vortex average profiles of potential temperature and $\mathrm{CH}_{4}$ (see also van Aalst et al. [2003]). We restricted the sampling to those profiles that were located within the vortex in the full altitude range between 100 and $10 \mathrm{hPa}$. Inner vortex air was selected by sampling within the area bordered by the steepest gradient in PV, according to the ECMWF forecasts.

Figure 7 shows that, except for the "Gl_96" run, the calculated descent rates during the winter agree quite well with 

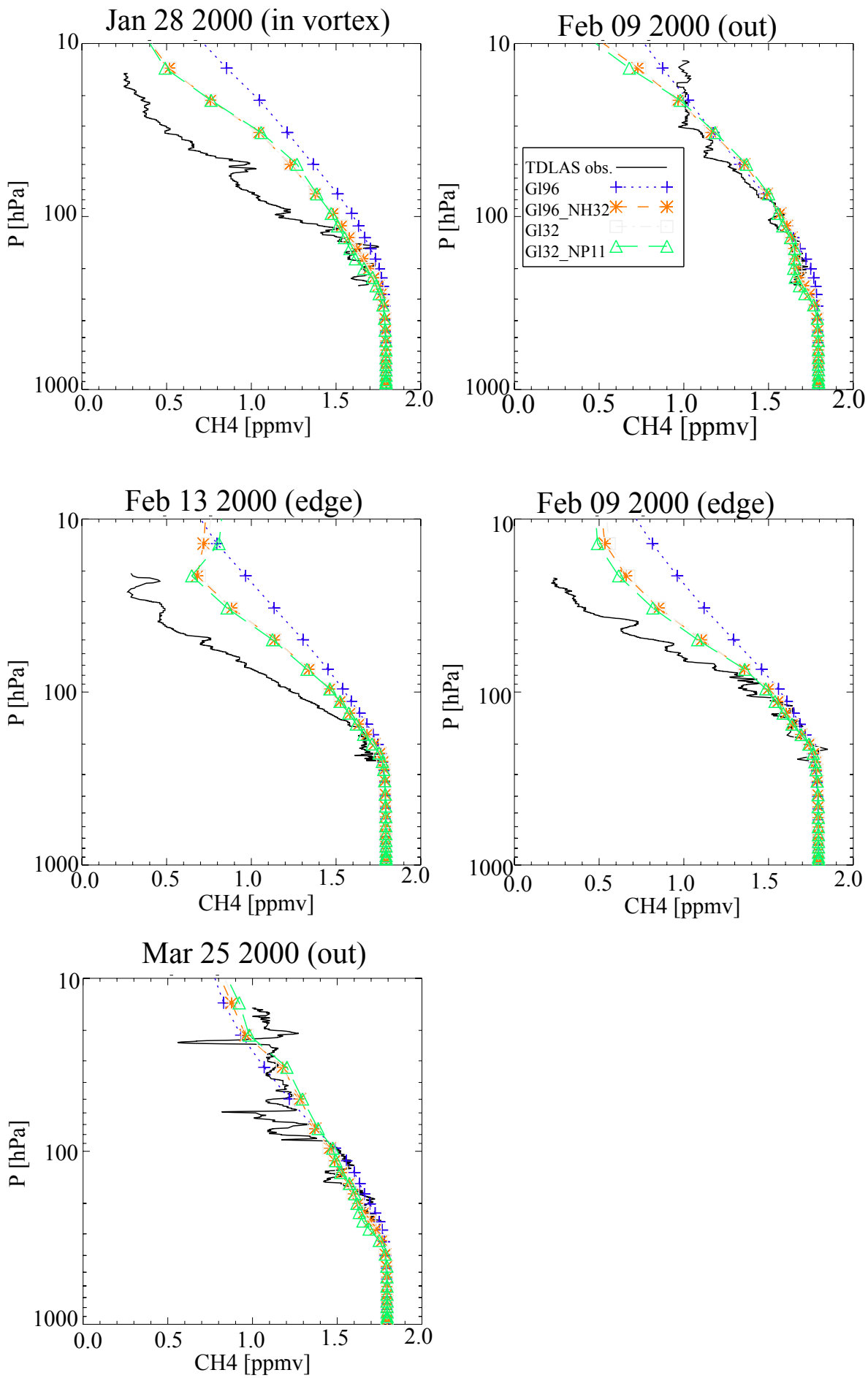

Fig. 4a. Modeled $\mathrm{CH}_{4}$ [ppmv] compared to TDLAS profiles, on 28 January, 9, 13 and 27 February and 25 March 2000.

those observed, except in the layer below $\theta \sim 450 \mathrm{~K}$, which is the layer undergoing the highest ozone loss. The discrepancy increases closer to the vortex lower boundary, i.e. $\sim 400 \mathrm{~K}$, especially in early winter. Largest descent takes places from December to January, slowing down in February and being close to zero after the first of March. Increasing the horizontal resolution in the zooming experiments, either in the tropics or in the polar region, has no effect on these results.

Initially, modeled potential temperature on 1 December 1999 has been synchronized with the observed $\theta$ profiles. 

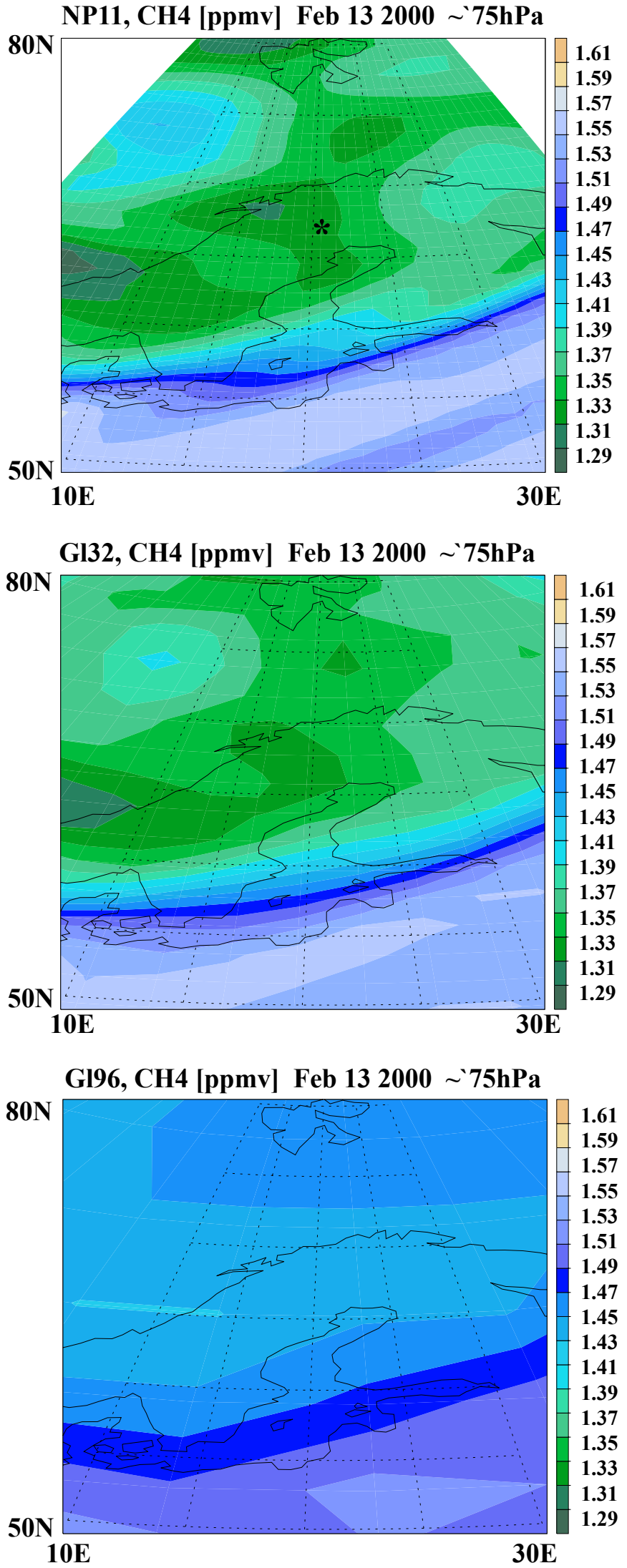

Atmos. Chem. Phys., 3, 1833-1847, 2003
Fig. 4b. Horizontal field of $\mathrm{CH}_{4}$ [ppmv] around Kiruna on 13 February 2000, at a pressure level of approximately $75 \mathrm{hPa}$. The three different model runs, NP_11, Gl_32 and Gl_96 show how horizontal gradients across the vortex edge are affected by the model resolution. 

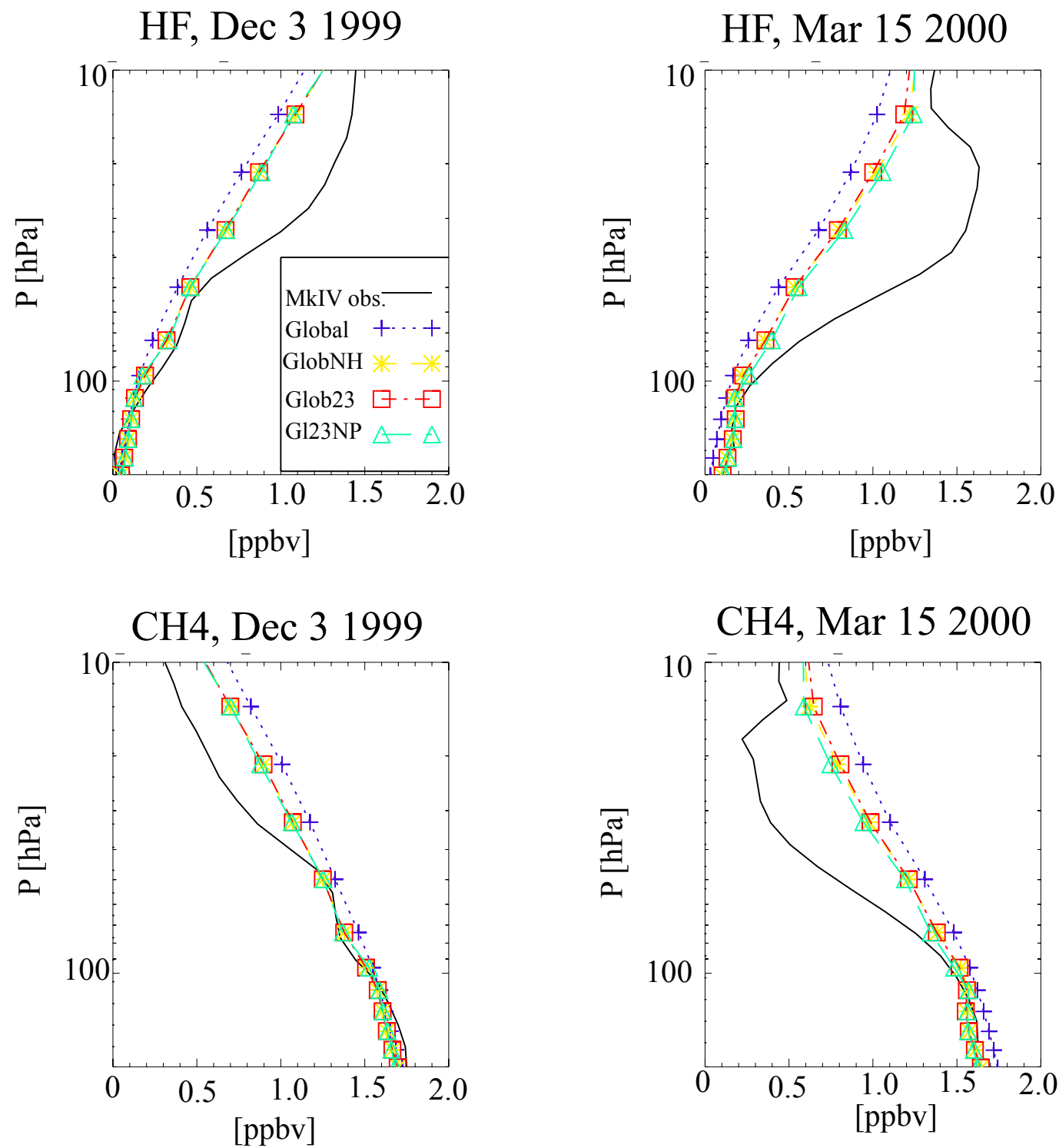

Fig. 5. Modeled HF [ppbv] and $\mathrm{CH}_{4}$ [ppmv] compared to MkIV profiles on 3 December 1999 and 15 March 2000.

Note that at the start of this calculation on 1 December, the offset in potential temperature for comparable $\mathrm{CH}_{4}$ volume mixing ratios is about $50 \mathrm{~K}$ above $500 \mathrm{~K}$. Around $450 \mathrm{~K}$ the offset is $20 \mathrm{~K}$, whereas the offset has disappeared around $400 \mathrm{~K}$ and layers below. Thus, the model does not simulate the tracer fields above $450 \mathrm{~K}$ correctly, at the start of this comparison on 1 December. This is in agreement with the modeled overestimation of $\mathrm{CH}_{4}$ and underestimation of $\mathrm{HF}$ with respect to the MkIV observations on 3 December, illustrated in Fig. 5.

Similar pre-winter offsets are also found with the 3-D CTMs REPROBUS and SLIMCAT using the same set of observations (Greenblatt et al., 2002). Greenblatt et al. (2002) compared modeled and observed descent rates in a similar way as discussed here. Both models showed similar descent rates as TM5, although REPROBUS descent is somewhat faster than the observed descent in the beginning of winter in the lower stratosphere. In addition, similar results are found with the MA-ECHAM model (van Aalst et al., 2003).

\subsection{Sensitivity of the initialization}

The model validation gives arguments to question the influence of the initial fields on the tracer distribution, as mentioned earlier. The initialization of the model on 1 September 1999 was based on the HALOE observations of August and September 1999. The northernmost latitude in this field is $73.9^{\circ} \mathrm{N}$. Therefore the species concentrations in the polar region outside the observed area were extrapolated from this 

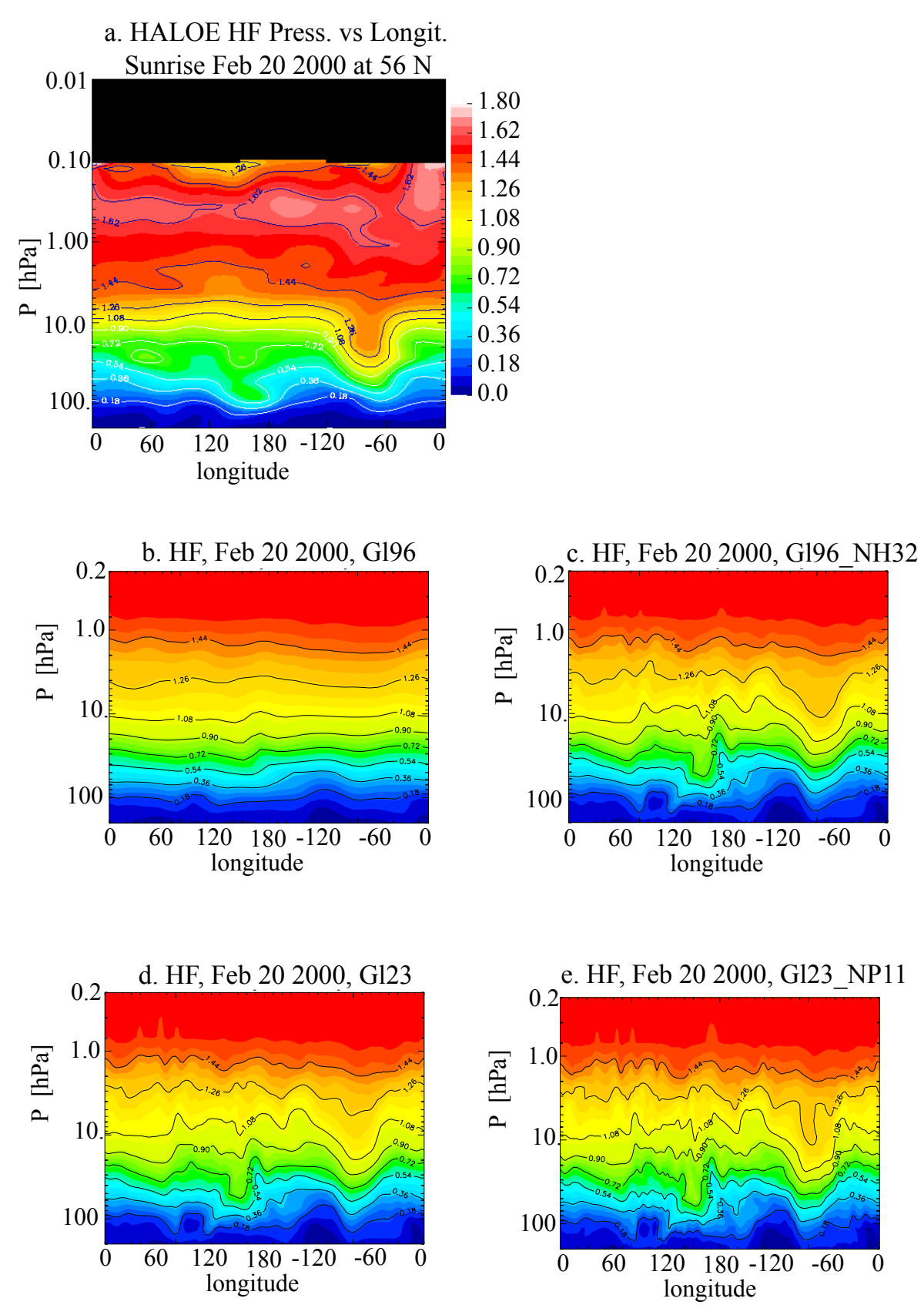

Fig. 6. Modeled HF [ppbv] compared to HALOE observations on 00-02-20, longitudinal cross section at $56^{\circ} \mathrm{N}$.

latitude. Despite this caveat, the method was applied to use as much observations as possible. Another option for initialization is the use of 3-D model output fields of full chemistry runs.

To test the impact of the initial fields we have performed a run with the Gl32 resolution, starting on 20 October 1999 and using an initialization provided by the full chemistry ARPROBUS climate model (WMO, 1999). A CTM model study using the same initialization and meteorological input showed a good agreement with inner vortex $\mathrm{CH}_{4}$ profiles (G. Barthet and F. Lefèvre, personal communication).
Figure 8 shows a comparison with the TDLAS and MkIV balloon observations similar to Figs. 4a and 5, with the old and new initialization. The new initialization has resulted in consequently lower $\mathrm{CH}_{4}$ concentrations. Inside the vortex, this means that the model gives more realistic results. The deviation with the two TDLAS profiles sampled outside the vortex is small as well, in both model runs.

Figure 9 shows the dependence of the correlation between HALOE observations and TM5 results on the initialization. All data from December 1999- March 2000, north of 30?N have been included. As mentioned earlier, the bulk of these 

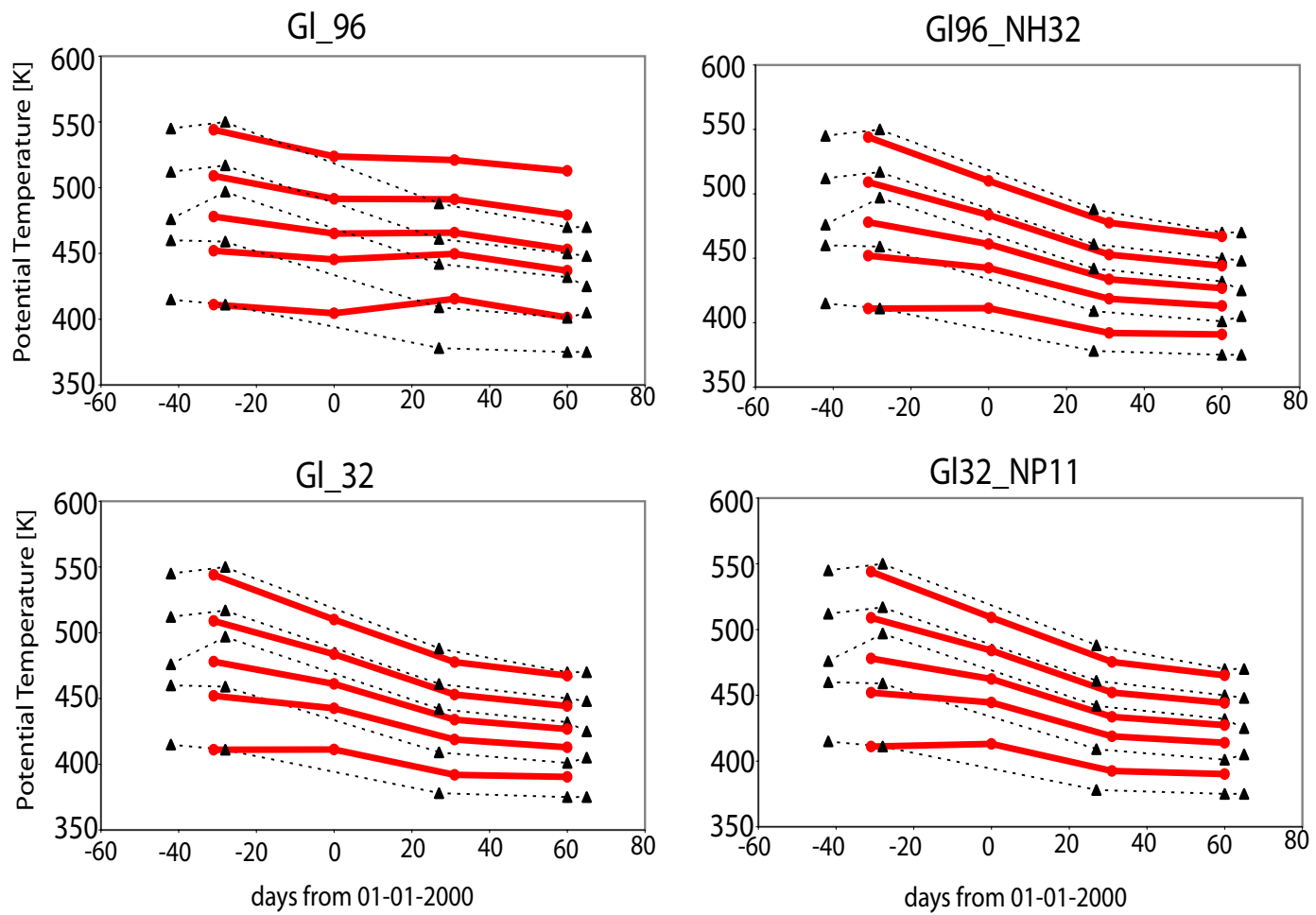

Fig. 7. Potential temperature throughout the winter of 1999-2000 along $\mathrm{CH}_{4}$ isopleths for observations (Greenblatt et al., 2002) in blackdotted lines, with the triangles representing the profile observations, and for model results on each first day of the month (red circles connected by solid lines) from all zooming options.

observations are outside the polar vortex. From these results it can be seen that the original HALOE initialization gives a slightly better correlation with the observations. The ARPROBUS initialization gives lower model concentrations. In agreement with the HF comparisons (Figs. $3 \mathrm{a}, \mathrm{b}$ and $\mathrm{c}$ ), the samples showing overestimation all originate from the polar vortex. The shift caused by the ARPROBUS initialisation results in better agreement for polar vortex air and slightly worse agreement for extra-vortex air, although the correlation remains good. Thus, this figure clearly shows that the initialization does have an effect on the results. However, it does not affect the relative difference between mid-latitudes and the polar vortex.

\section{Discussion and conclusions}

We have evaluated the 3D chemistry transport model TM5 with the stratospheric tracers $\mathrm{HF}$ and $\mathrm{CH}_{4}$ during the Arctic winter of 1999/2000 and tested the new model zooming algorithm. The results of our model experiments, applying three different resolutions of $6^{\circ} \times 9^{\circ}, 3^{\circ} \times 2^{\circ}$ and $1^{\circ} \times 1^{\circ}$, have been compared to observations. As can be expected, the coarsest resolution of $6^{\circ}$ latitude by $9^{\circ}$ longitude produces relatively large errors. The longitudinal variation as compared to the HALOE HF observations near the vortex edge, and inner vortex descent are simulated unrealistically with this resolution. Such discrepancies should be considered since many climate model integrations are performed with similar resolutions (e.g. Pawson et al., 2000, Austin et al., 2003). Outside the vortex, the results of the $2^{\circ}$ by $3^{\circ}$ run agree better with the observations. Remarkably, the tracer profiles are similar if a $6^{\circ}$ by $9^{\circ}$ resolution is used in the southern hemisphere and tropics instead of $2^{\circ}$ by $3^{\circ}$. Apart from the significant improvement when increasing the resolution from $9^{\circ}$ by $6^{\circ}$ to $3^{\circ}$ by $2^{\circ}$, further increase of the horizontal resolution does not improve, or worsen, the comparison with the observations in this model set-up. Nevertheless, differences between the $3^{\circ} \times 2^{\circ}$ and the $1^{\circ} \times 1^{\circ}$ runs arise close to large gradients such as the vortex edge, which may be important when species with larger concentration gradients are studied.

The close resemblance between the results of the uniform $3^{\circ} \times 2^{\circ}$ run and the northern hemisphere $3^{\circ} \times 2^{\circ}$ run shows the applicability of the TM5 zooming algorithm. Thus, highresolution simulations become feasible. It is intended to compare these simulations to observations from measurements campaigns and satellite instruments in the (lower) stratosphere.

The model comparisons with balloon and satellite profiles measured inside the vortex give an underestimation of HF and subsequent overestimation of $\mathrm{CH}_{4}$ for each resolution. 

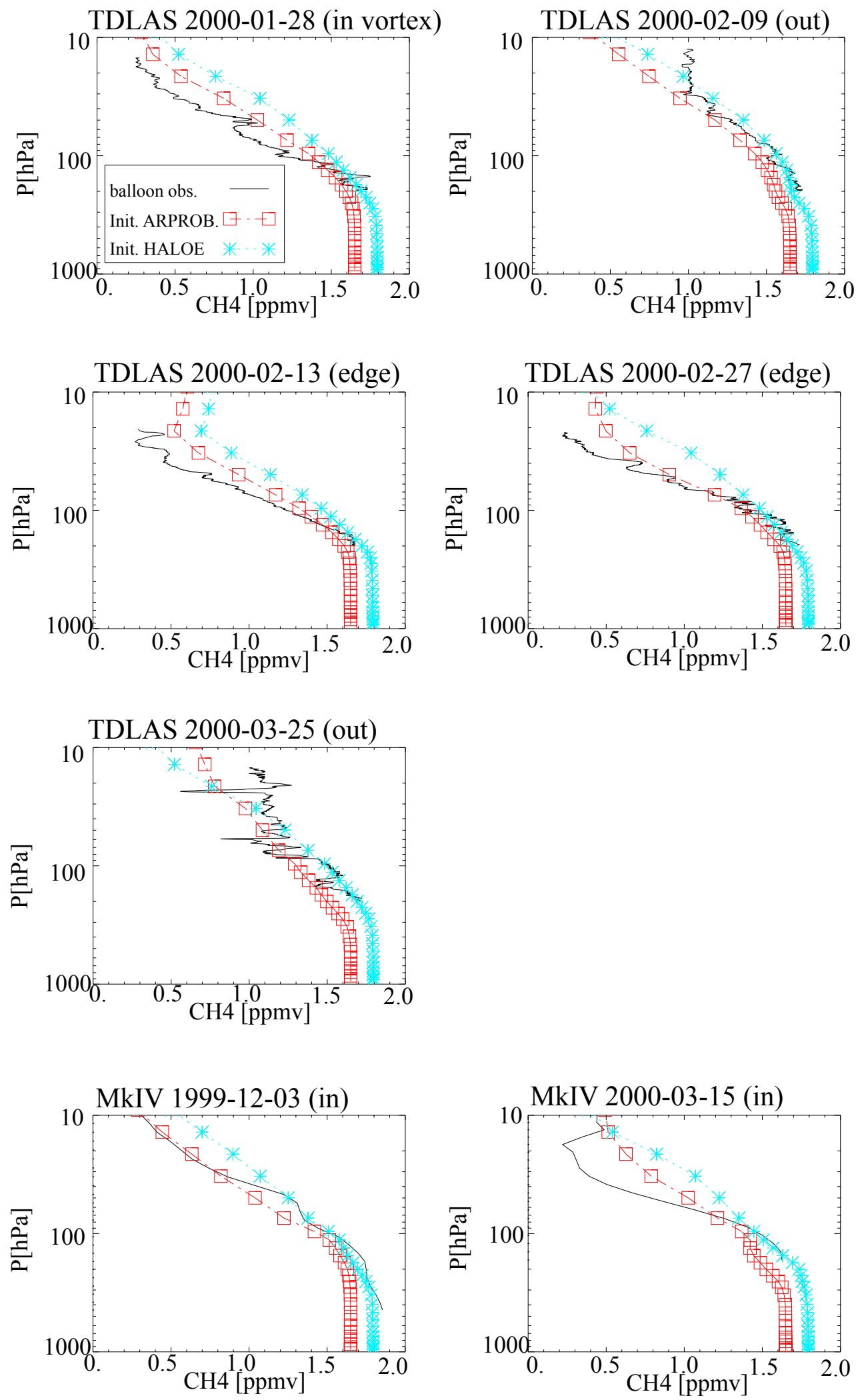

Fig. 8. TDLAS and MkIV balloon-borne observations of $\mathrm{CH}_{4}$ from 3 December to 25 March 2000 compared to TM5 output with two different initialisations. The TDLAS measurements are both inside and outside the vortex, whereas the MkIV measurements are all sampled inside the vortex. 


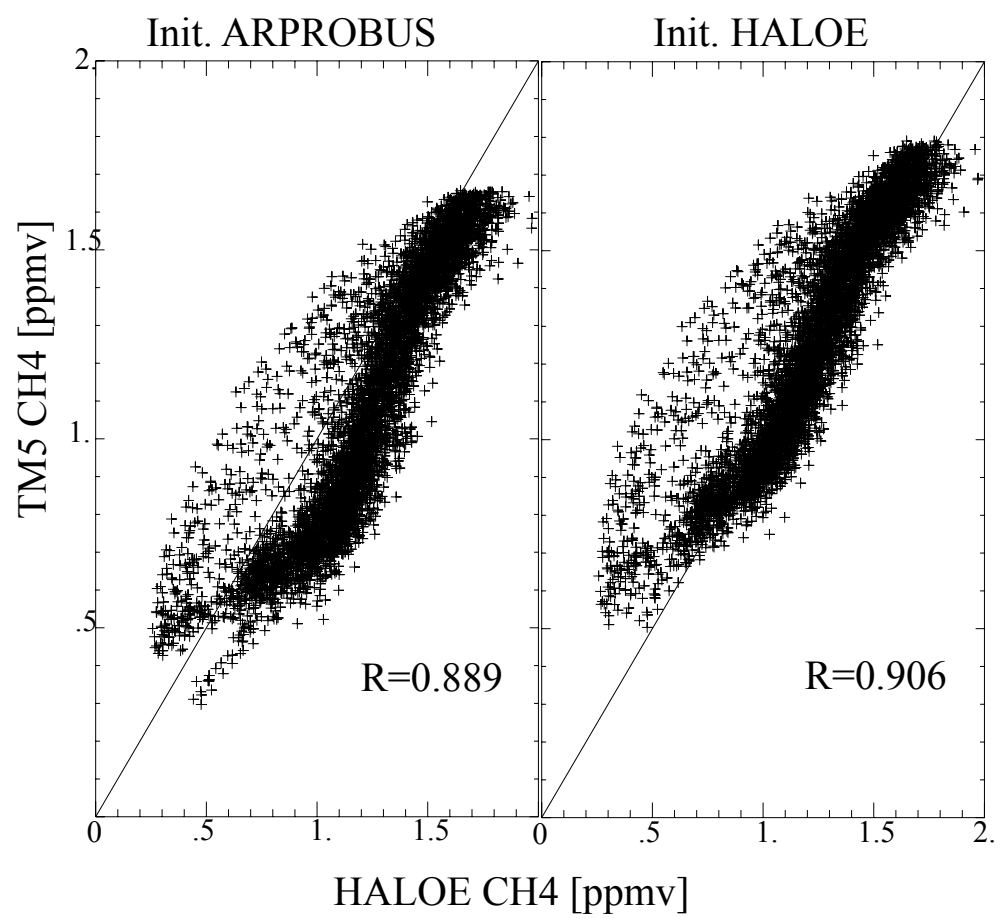

Fig. 9. Correlation between HALOE observations and TM5 model output from December 1999 to March 2000, for two different initializations. These are described in detail in the text.

Our model analysis shows that these model deviations are restricted to polar vortex air. Outside, the $\mathrm{HF}$ and $\mathrm{CH}_{4}$ distribution are simulated in agreement with observations.

Comparisons with observed tracer isopleths show reasonable agreement in vortex descent for the higher grid resolutions. However, this comparison does not separate horizontal and vertical model transport, so that both may have contributed to the discrepancies. A way to separate horizontal and vertical transport was described by Considine et al. (2003). They isolated the vertical model transport by eliminating tracer concentration gradients along the isentropic model levels. Their conclusions point towards compensating errors in the vertical and the horizontal transport.

Additional aspects of the exerimental set-up may have contributed to the inner vortex discrepancy. Firstly, it can be ruled out that these discrepancies are caused by uncertainties in boundary conditions at the top and bottom of the model and tropospheric rain-out, as was investigated by van Aalst et al. (2003).

Secondly, some of the comparisons between model and measurements in early winter suggest that the initialization could be in error. The combined time series of the calculated and observed $\mathrm{CH}_{4}$ and $\mathrm{HF}$ profiles (Figs. 4a and 5) show that the inner vortex discrepancy already starts during early winter (note that the discrepancy is already present on 3 December). We tested whether a different initialization was able to explain the discrepancies. A better agreement with observations was indeed achieved within the vortex region, explaining the early winter offset. It, however, leads to a worse agreement at mid-latitudes (Fig. 9). Thus, an inaccurate initialization may lead to an offset, but it cannot fully explain the discrepancies found in the vertical gradient and over time.

Another possible reason for the model discrepancies could be found in the vortex formation. The ECWMF data extend only to $0.2 \mathrm{hPa}$ where observations become sparse. Since the vortex was already formed on 1 November in the upper stratosphere (Manney and Sabutis, 2000), this region is very critical when simulating the early winter vortex. It may indicate that either diabatic descent or horizontal transport is not well represented in the model, thus the underlying meteorology from ECMWF does not properly represent the downward or horizontal transport in the polar vortex. In this study, we increased the horizontal resolution of TM5 up to $1^{\circ} \times 1^{\circ}$ for a relatively large area (northward of $30^{\circ} \mathrm{N}$ ). Nevertheless, the discrepancies remain, which may be an indication that the accuracy of the mass fluxes as provided by ECMWF is insufficient (Considine et al., 2003; Plumb et al., 2002). Recent studies indicate that errors in the stratospheric circulation in assimilated meteo fields exist that may play a crucial role here, e.g. during the formation of the winter vortex (Kawa et al., 2003).

Finally, other model characteristics such as the vertical resolution, the advection scheme and the reduced grid used in the polar region have not been investigated. All of these parameters are being addressed with the TM5 model by 
including all (60) ECMWF model layers, by removal of the reduced grid and by using a higher order advection scheme (Krol et al., manuscript in preparation).

Acknowledgements. The authors wish to express their gratitude to the HALOE team for providing us with their observations. We thank the other members of the TDLAS and MkIV teams, especially I. H. Howieson, N. R. Swann and P. T. Woods from the National Physical Laboratory. Benedikt Steil, Christoph Brühl from the Max Planck Institute for Chemistry in Mainz and J. Greenblatt, at Princeton University, are thanked for fruitful discussions. The second initialization was provided by Gwenael Barthet and Franck Lefèvre, for which we thank them. We also thank Arjo Segers and Peter van Velthoven from the Royal Netherlands Meteorological Institute for providing the software to process the meteorological fields. Bram Bregman is funded by the EC project TOPOZ III EVK2-CT-200100102.

\section{References}

Austin, J., Shindell, D., Beagley, S. R., Brühl, C., Dameris, M., Manzini, E., Nagashima, T., Newman, P., Pawson, S., Pitari, G., Rozanov, E., Schnadt, C., and Shepherd, T. G.: Uncertainties and assessments of chemistry-climate models of the stratosphere, Atmos. Chem. Phys., 3, 1-27, 2003.

Bregman, A., Lelieveld, J., van den Broek, M., Fischer, H., Siegmund, P., and Bujok, O.: The $\mathrm{N}_{2} \mathrm{O}$ and $\mathrm{O}_{2}$ relationship for mixing processes as represented by a three-dimensional chemistrytransport model, J. Geophys. Res., 105, 17 279-17 290, 2000.

Bregman, A., Krol, M. C., Teyssedre, H., Norton, W. A., Iwi, A., Chipperfield, M., Pitari, G., Sundet, J. K., and Lelieveld, J.: Chemistry-Transport model comparison with ozone observations in the midlatitude lowermost stratosphere, J. Geophys. Res., 106, 17 479-17 496, 2001.

Bregman, A., Segers, A., Krol, M., Meijer, E., and van Velthoven, P.: On the use of mass-conserving wind fields in chemistrytransport models, Atm. Chem. Phys., 3, 447-457, 2003.

Chipperfield, M. P., Burton, M., Bell, W., Walsh, C. P., Blumenstock, T., Coffey, M. T., Hannigan, J. W., Mankin, W. G., Galle, B., Mellqvist, J., Mahieu, E., Zander, R., Notholt, J., Sen, B., and Toon, G. C.: On the use of HF as a reference for the comparison of stratospheric observations and models, J. Geophys. Res., 102, 12 901-12 919, 1997.

Chipperfield, M. P. and Jones, R. L.: Relative influences of atmospheric chemistry and transport on Arctic ozone trends, Nature, 400, 551-553, 1999.

Considine, D. B., Kawa, S. R., Schoeberl, M. R., and Douglass, A. R.: $\mathrm{N}_{2} \mathrm{O}$ and $\mathrm{NO}_{\mathrm{y}}$ observations in the 1999/2000 Arctic polar vortex: Implications for transport processes in a CTM, J. Geophys. Res., 108, 10.1029/2002JD002525, 2003.

Edouard, S., Legras, B., Lefèvre, F., and Eymard, R.: The effect of small-scale inhomogeneities on ozone depletion in the Arctic, Nature, 384, 444-446, 1996.

Garcelon, S., Gardiner, T. D., Hansford, G. M., Harris, N. R. P., Howieson, I. H., Jones, R. L., McIntyre, J. D., Pyle, J. A., Robinson, A. D., Swann, N. R., and Woods, P. T.: Investigation of $\mathrm{CH}_{4}$ and $\mathrm{CFC}-11$ vertical profiles in the Arctic vortex during the SOLVE/THESEO 2000 campaign, poster presentation at EGS, Nice, 2002.
Greenblatt, J. B., Jost, H. J., Loewenstein, M., Podolske, J. R., Hurst, D. F., Elkins, J. W., Schauffler, S. M., Atlas, E. L., Herman, R. L., Webster, C. R., Bui, T. P., Moore, F. L., Ray, E. A., Oltmans, S., Voemel, H., Blavier, J.-F., Sen, B., Stachnik, R. A., Toon, G. C., Engel, A., Mueller, M., Schmidt, U., Bremer, H., Pierce, R. B., Sinnhuber, B.-M., Chipperfield, M., Lefevre, F.: Tracer-based determination of vortex descent in the 1999-2000 Arctic winter, J. Geophys. Res., 107, 10.1029/201JD000937, 2002.

Hall, T. M., Waugh, D. W., Boering, K. A., Plumb, R. A.: Evaluation of transport in stratospheric models, J. Geophys. Res., 104, 18 815-18 839, 1999.

Kawa, S. R., Bevilacqua, R. M., Margitan, J. J., Douglass, A. R., Schoeberl, M. R., Hoppel, K. W., and Sen, B.: Interaction between dynamics and chemistry of ozone in the setup phase of the Northern Hemisphere polar vortex, J.Geophys. Res., 108, 10.1029/2001JD001527, 2003.

Krol, M. C., Peters, W., Berkvens, P. J. F., and Botchev, M. A.: A New Algorithm for two-way nesting in global models: Principles and Applications, in: Proc. 2nd Int. Conf. Air Pollution Modeling and Simulation, edited by Sportisse, B., 9-12 April 2001, Champs-sur-Marne, Springer, Berlin, Heidelberg and New York, 225-235, 2002.

Krol, M. C., Lelieveld, J., Oram, D. E., Sturrock, G. A., Penkett, S. A., Brenninkmeier, C. A. M., Gros, V., Williams, J., and Scheeren, H. A.: Continuing emissions of methyl chloroform from Europe, Nature, 421, 131-135, 2003.

Mahowald, N. M., Plumb, R. A., Rasch, P. J., del Corral, J., Sassi, F., and Heres, W.: Stratospheric transport in a 3dimensional isentropic coordinate model, J. Geophys. Res., 107, 10.1029/2001JD001313, 2002.

Manney, G. L. and Sabutis, J. L.: Development of the polar vortex in the 1999-2000 Arctic winter stratosphere, Geophys. Res. Lett., 27, 2589-2592, 2000.

Pawson, S., Kodera, K., Hamilton, K., Shepherd, T. G., Beagley, S. R., Boville, B. A., Farrara, J. D., Fairlie, T. D. A., Kitoh, A., Lahoz, W. A., Langematz, U., Manzini, E., Rind, D. H., Scaife, A. A., Shibata, K., Simon, P., Swinbank, R., Takacs, L., Wilson, R. J., Al-Saadi, J. A., Amodei, M., Chiba, M., Coy, L., de Grandpré, J., Eckman, R. S., Fiorino, M., Grose, W. L., Koide, H., Koshyk, J. N., Li, D., Lerner, J., Mahlman, J. D., McFarlane, N. A., Mechoso, C. R., Molod, A., O’Neill, A., Pierce, R. B., Randel, W. J., Rood, R. B., and Wu, F.: The GCM-Reality Intercomparison Project for SPARC (GRIPS): Scientific issues and initial results, Bull. Am. Meteor. Soc., 81, 781-796, 2000.

Peters, W., Krol, M., Dentener, F., Thompson, A. M., and Lelieveld, J.: Chemistry-transport modeling of the satellite observed distribution of tropical tropospheric ozone, Atmospheric Chemistry and Physics, 2, 103-120, 2002.

Plumb, R. A., Heres, W., Neu, J. L., Mahowald, N. M., del Corral, J., Toon, G. C., Ray, E. R., Moore, F., Andrews, A. E.: Global tracer modeling during SOLVE: High latitude descent and mixing, J. Geophys. Res., 107, 10.1029/2001JD001023, 2002.

Randel, W. J., Wu, F., Russell III, J. M., Roche, A., and Waters, J. W.: Seasonal cycles and QBO variations in stratospheric $\mathrm{CH}_{4}$ and $\mathrm{H}_{2} \mathrm{O}$ observed in UARS HALOE data, J. Atmos. Sci., 55, 163-185, 1998.

Rind, D., Lerner, J., Shah, K., and Suozzo, R.: Use of on-line tracers as a diagnostic tool in general circulation model development 2 , 
Transport between the troposphere and stratosphere, J. Geophys. Res., 104, 9151-9167, 1999.

Russell, G. L. and Lerner, J. A.: A new finite-differencing scheme for the tracer transport equation, J. Appl. Meteorol., 20, 14831498, 1981.

Russell III, J. M., Gordley, L. L., Park, J. H., Drayson, S. R., Hesketh, D. H., Cicerone, R. J., Tuck, A. F., Frederick, J. E., Harries, J. E., and Crutzen, P. J.: The Halogen Occultation Experiment, J. Geophys. Res., 98, 10777-10 797, 1993.

Russell III, J. M., Deaver, L. E., Luo, M., Cicerone, R. J., Park, J. H., Gordley, L. L., Toon, G. C., Gunson, M. R., Traub, W. A., Johnson, D. G., Jucks, K. W., Zander, R., and Nolt, I. G.: Validation of hydrogen fluoride measurements made by the Halogen Occultation Experiment from the UARS Platform, J. Geophys. Res., 101, $10163-10$ 174, 1996.

Searle, K. R., Chipperfield, M. P., Bekki, S., and Pyle, J. A.: The impact of spatial averaging on calculated polar ozone loss: I. Model Experiments, J. Geophys. Res., 103, 25 397-25 408, 1998.

Tiedtke, M.: A comprehensive mass flux scheme for cumulus parameterization in large-scale models, Mon. Wea. Rev., 117, 1779-1800, 1989.
Toon, G. C., Blavier, J.-F., Sen, B., Margitan, J. J., Webster, C. R., May, R. D., Fahey, D., Gao, R., Del Negro, L., Proffitt, M., Elkins, J., Romashkin, P. A., Hurst, D. F., Oltmans, S., Atlas, E., Schauffler, S., Flocke, F., Bui, T. P., Stimpfle, R. M., Boone, G. P., Voss, P. B., Cohen, R. C.: Comparison of MkIV balloon and ER-2 aircraft measurements of atmospheric trace gases, J. Geophys. Res., 104, 26 779-26 790, 1999.

Van Aalst, M. K., van den Broek, M. M. P., Bregman, A., Brühl, C., Steil, B., Roelofs, G. J., and Lelieveld, J.: Trace gas transport in the 1999/2000 Arctic vortex: comparison of nudged GCM runs with observations, Atm. Chem. Phys. Discuss., 3, 2465-2497, 2003.

Van den Broek, M. M. P., Bregman, A., and Lelieveld, J.: Model study of stratospheric chlorine activation and ozone loss during the 1996/1997 winter, J. Geophys. Res., 105, 28 961-28 977, 2000.

World Meteorological Organization (WMO): Scientific Assessment of ozone depletion: 1998, Global ozone research and monitoring project, WMO Rep. 44, 1999. 